University of Windsor

Scholarship at UWindsor

$10-13-2005$

\title{
Audition in sciaenid fishes with different swim bladder-inner ear configurations
}

John U. Ramcharitar

Dennis M. Higgs

University of Windsor

Arthur N. Popper

Follow this and additional works at: https://scholar.uwindsor.ca/biologypub

Part of the Biology Commons

\section{Recommended Citation}

Ramcharitar, John U.; Higgs, Dennis M.; and Popper, Arthur N., "Audition in sciaenid fishes with different swim bladder-inner ear configurations" (2005). Journal of the Acoustical Society of America, 1, 119, 439-443.

https://scholar.uwindsor.ca/biologypub/99

This Article is brought to you for free and open access by the Department of Biological Sciences at Scholarship at UWindsor. It has been accepted for inclusion in Biological Sciences Publications by an authorized administrator of Scholarship at UWindsor. For more information, please contact scholarship@uwindsor.ca. 


\title{
Audition in sciaenid fishes with different swim bladder-inner ear configurations
}

\author{
John U. Ramcharitar, ${ }^{\text {a) }}$ Dennis M. Higgs, ${ }^{\text {b) }}$ and Arthur N. Popper \\ Department of Biology \& Neuroscience and Cognitive Science Program, University of Maryland, \\ College Park, Maryland 20742
}

(Received 7 April 2005; revised 23 September 2005; accepted 13 October 2005)

\begin{abstract}
We investigated how morphological differences in the auditory periphery of teleost fishes may relate to hearing capabilities. Two species of western Atlantic sciaenids were examined: weakfish (Cynoscion regalis, Block and Schneider) and spot (Leiostomus xanthurus, Lacepede). These species differ in the anatomical relationship between the swim bladder and the inner ear. In weakfish, the swim bladder has a pair of anterior horns that terminate close to the ear, while there are no extensions of the swim bladder in spot. Thus, the swim bladder in spot terminates at a greater distance from the ear when compared to weakfish. With the use of the auditory brainstem response technique, Cynoscion regalis were found to detect frequencies up to $2000 \mathrm{~Hz}$, while Leiostomus xanthurus detected up to $700 \mathrm{~Hz}$. There were, however, no significant interspecific differences in auditory sensitivity for stimuli between 200 and $700 \mathrm{~Hz}$. These data support the hypothesis that the swim bladder can potentially expand the frequency range of detection. (C) 2006 Acoustical Society of America. [DOI: 10.1121/1.2139068]
\end{abstract}

PACS number(s): 43.64.-q, 43.64.Ri, 43.64.Ha, 43.66.Cb [WWA] Pages: 439-443

\section{INTRODUCTION}

Fish hearing may involve two paths of sound stimulation in the ear (Fay and Popper, 1974). All fish are able to use a "direct" stimulation pathway where the displacement component of sound waves causes relative motion between the otoliths and sensory epithelia of the inner ear. Such direct detection primarily works at frequencies below 500-600 Hz (Dijkgraaf, 1960; Popper and Fay, 1999). Many species (often referred to as "hearing specialists") have also evolved the ability to use an "indirect" detection pathway for hearing by reradiating the pressure component of sound waves to stimulate the inner ear (Dijkgraaf, 1960; van Bergeijk, 1967; Fay and Popper, 1974; Kalmijn, 1988; Rogers and Cox, 1988), thereby extending the detectable auditory bandwidth to several thousand Hertz (e.g., von Frisch, 1938; McCartney and Stubbs, 1971; Fay and Popper, 1974; Hawkins and Myrberg, 1983; Mann et al., 1997). It has been postulated that this pressure detection occurs via swim bladders and other gas bubbles which are located close to the ear or which are brought into proximity to the ear by specialized extensions (e.g., Dijkgraaf, 1960; Fay and Popper, 1974; Denton and Blaxter, 1976; Coombs and Popper, 1979; Crawford, 1993; Yan et al., 2000).

The sciaenids are a very large group of commercially important marine fishes that have a diversity of swim bladder configurations. Among western Atlantic sciaenids, there are three general types of swim bladder-ear relationships. In species such as weakfish (Cynoscion regalis), spotted seatrout

\footnotetext{
${ }^{a}$ Current address: Department of Anatomy and Cell Biology, The George Washington University, 2300 Eye St., Washington, DC 20037. Electronic mail: anajxr@gwumc.edu

${ }^{b)}$ Current address: Department of Biology, University of Windsor, Windsor, CA N9B 3P4.
}

(Cynoscion nebulosus), and silver perch (Bairdiella chyrsoura), the swim bladder has anterior horns that terminate close to the ear (Chao, 1978; Ramcharitar et al., 2004). In other species such as the spot (Leiostomus xanthurus) and black drum (Pogonias chromis), the swim bladders are further from the ear, and they lack anterior horns or diverticulae (Chao, 1978; Davorec, 1983; Ramcharitar and Popper, 2004). Species such as Atlantic croaker (Micropogonias undulatus) represent an intermediate group in which the swim bladder possesses anteriorly directed diverticulae that approach but do not touch the ear (Chao, 1978; Ramcharitar and Popper, 2004). This interspecific diversity in swim bladder-inner ear relationship makes sciaenids good models for investigating structure-function relations in the teleost auditory system.

Ramcharitar et al. (2001) demonstrated that a correlation exists between swim bladder-ear configuration and two aspects of inner ear morphology in several sciaenid species. It was found that $M$. undulatus and $C$. nebulosus have significant rostral expansion of their saccular sensory epithelia, as well as more stereocilia per sensory hair cell ciliary bundle on these epithelia, than do L. xanthurus and kingfish (Menticirrhus americanus). These interspecific variations in inner ear ultrastructure correlated with swim bladder-ear relationships among the four species, as the swim bladder of both $M$. undulatus and $C$. nebulosus have anterior extensions that approach the ear, while those of L. xanthurus and M. americanus do not terminate near the ear.

In addition, recent studies have shown correlations between structure and function in the auditory systems of several sciaenid species (Ramcharitar et al., 2004; Ramcharitar and Popper, 2004). Bairdiella chrysoura, a sciaenid species with a close association between the swim bladder and inner ear and with several specializations of the otolithic end organs, responds to sounds up to $4 \mathrm{kHz}$ (Ramcharitar et al., 
2004). Also, hearing sensitivity of $B$. chrysoura is comparable to that of the goldfish, a well-known "hearing specialist" (Ramcharitar et al., 2004). It also has been demonstrated that sciaenid species with different swim bladder-inner ear arrangements also show differences in frequency selectivity (Ramcharitar and Popper, 2004).

The vast majority of studies on the potential contribution of the swim bladder to audition have used species at the extremes of the spectrum of auditory capability (e.g., Fay and Popper, 1974; Denton and Blaxter, 1976; Crawford, 1993; Yan et al., 2000). Sciaenid fishes exhibit a continuum in the degree of separation between the swim bladder and the otic capsule, and, therefore, comparative work on these species may add critically to our understanding of form and function in the teleost inner ear. In this study, the auditory brainstem responses of $C$. regalis and $L$. xanthurus were investigated, and these data together with those of other sciaenids support a role for the swim bladder in frequency range of detection.

\section{MATERIALS AND METHODS}

All animals were obtained from the Rutger's Marine Field Station, Tuckerton, NJ or from the Delaware Bay (courtesy of the Public Service Enterprise Group). Ten individuals per species were used in this study. C. regalis were $7.2-12.0 \mathrm{~cm}$ total length, while $L$. xanthurus were $7.2-12.5 \mathrm{~cm}$ total length. Methods used have been described in detail in previous studies (Ramcharitar et al., 2004; Ramcharitar and Popper, 2004) and were approved by the University of Maryland Institutional Animal Care and Use Committee.

\section{A. Gross dissections}

After anesthesia and fixation, ventral dissections were performed to quantify swim bladder proximity to the ear. The swim bladder-ear distance was measured as the minimum distance between the rostral extent of the swim bladder and the caudal edge of the otic capsule. In the case of weakfish, this distance was measured from the rostral tips of the swim bladder horns. On average, five individuals per species (of comparable size) were used for these measurements.

The position of the brainstem was also determined using gross dissections. Dorsal dissections were performed to expose the brain and rostral region of the spinal cord. Once the brainstem was mapped, landmarks on the external surface of the fishes were then identified to make electrode placement consistent between physiology experiments.

\section{B. Auditory brainstem response}

Fish were suspended in a plastic bucket $(19 \mathrm{~L}$, depth $=45 \mathrm{~cm}$ ) filled with water above (about $35 \mathrm{~cm}$ ) an underwater speaker (UW-30, Underwater Sound Inc., Oklahoma City, OK, USA). A recording electrode was placed subdermally on the dorsal surface of the fish just over the brainstem, and a reference electrode was positioned approximately $1 \mathrm{~cm}$ rostral to this recording electrode. Additionally, there was a

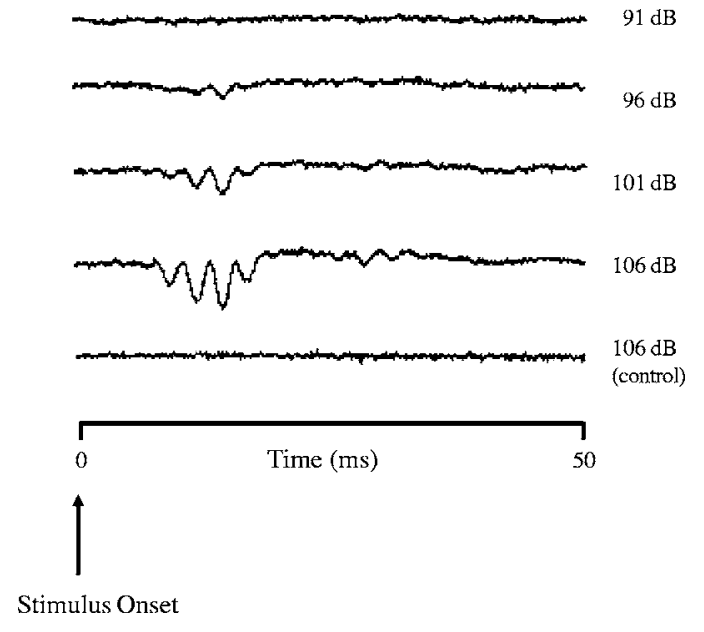

FIG. 1. Examples of ABR traces from Leiostomus xanthurus at a test frequency of $300 \mathrm{~Hz}$. Stimulus intensity levels are stated in $\mathrm{dB}(r e: 1 \mu \mathrm{Pa})$ to the right of each trace. The auditory threshold is defined as the minimum sound intensity level at which an ABR is evoked. In this example, the auditory threshold is judged to be $96 \mathrm{~dB}$ (re: $1 \mu \mathrm{Pa}$ ), the first trace showing a response. The ABR emerges as a series of downward negative peaks within the first $20 \mathrm{~ms}$ of stimulus onset (which is at $0 \mathrm{~ms}$ ). The bottom trace is from a dead fish at a test frequency of $300 \mathrm{~Hz}$ at $106 \mathrm{~dB}(r e: 1 \mu \mathrm{Pa})$.

ground electrode near the body of the fish. Electrodes were stainless steel (Rochester Electro-Medical Inc., Tampa, FL, USA) and insulated with fingernail polish.

Sounds were played and responses were collected using a Tucker-Davis Technologies Inc. (TDT; Gainesville, FL) physiological apparatus using SigGen and BioSig software (TDT). Acoustic stimuli were generated by a computer with TDT software and then delivered to the UW-30 underwater speaker via a power amplifier. Tone burst stimuli were used at $100-\mathrm{Hz}$ intervals from $200-1500 \mathrm{~Hz}$. Tones were $10 \mathrm{~ms}$ in duration with a $2-\mathrm{ms}$ rise and fall time. Sound intensity levels at each frequency were increased in $5 \mathrm{~dB}$ steps from 60 to $125 \mathrm{~dB}$ re: $1 \mu \mathrm{Pa}$ until a typical ABR waveform was observed (series of negative peaks within the first $20 \mathrm{~ms}$ of stimulus onset, see Fig. 1). The sound intensity levels used were checked and calibrated (calibration sensitivity of $-195 \mathrm{~dB}$ re: $1 \mathrm{~V} / \mu \mathrm{Pa} ; \pm 3 \mathrm{~dB}, 0.02-10 \mathrm{kHz}$, omnidirectional; model 902; Interocean Systems, Inc., San Diego, CA, USA). The lower and upper limits of the sound delivery system were determined to be 60 and $125 \mathrm{~dB}(r e: 1 \mu \mathrm{Pa})$, respectively. Signal waveform across the frequency and sound intensity range used were also analyzed periodically to ensure that distortion did not occur. For each test condition, 400 responses of alternating phase were averaged.

\section{Controls}

Occasionally our system was checked using goldfish, a species for which there are established behavioral audiograms (reviewed in Fay, 1988; Higgs, 2002). In each test case, the expected frequency range of detection was achieved for this teleost. On several occasions, experiments were performed using euthanized fish and also with no fish in the setup in order to establish that the identified ABR responses 


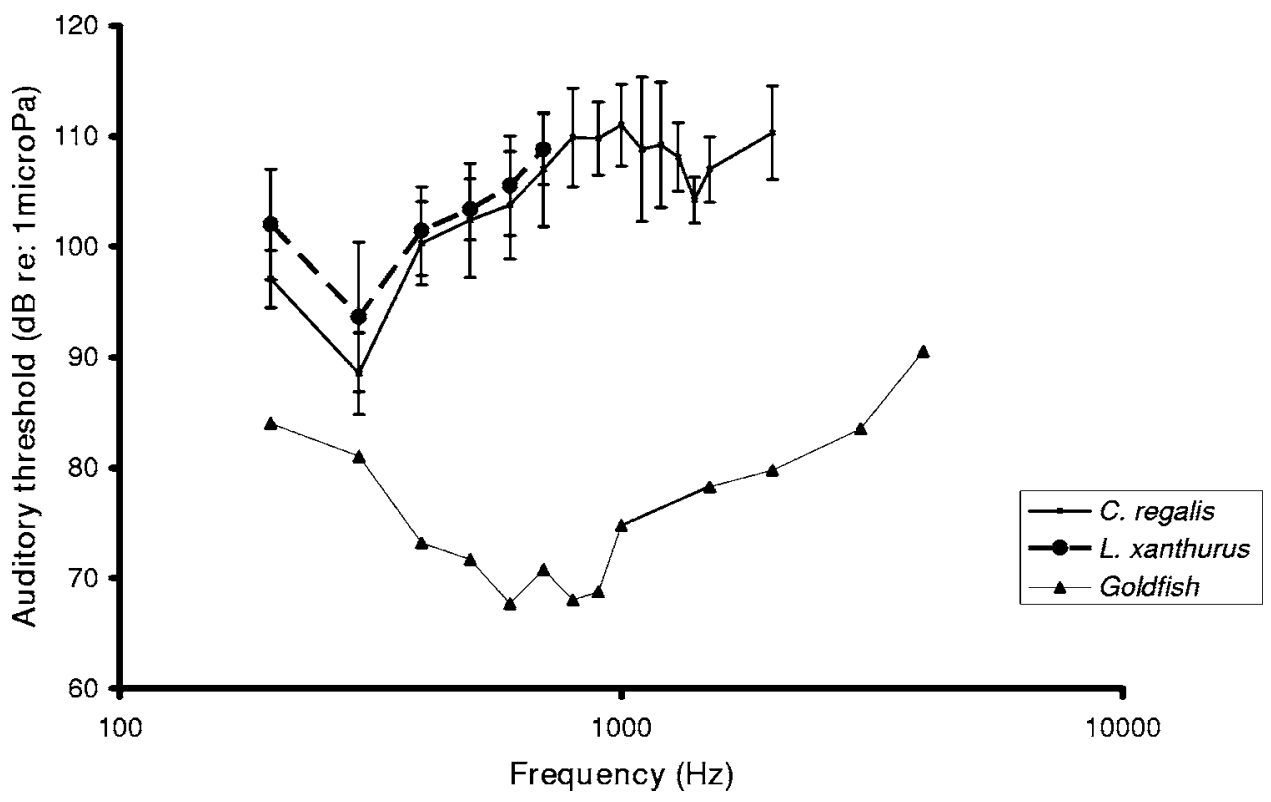

FIG. 2. Audiograms of Leiostomus xanthurus and Cynoscion regalis. Auditory thresholds are expressed as "mean \pm standard deviation." The frequency axis is in log scale. Weakfish detected tones up to $2 \mathrm{kHz}$ while spot were sensitive to signals up to $700 \mathrm{~Hz}$. The audiogram of goldfish is included for comparison and calibration (Higgs, 2002). For all three species, the same apparatus, stimuli, and auditory threshold criteria were used.

were not artifacts. These tests confirmed that our data were reliable. Responses were never obtained from dead fish (Fig. 1) or when fish were not in the apparatus.

\section{Statistical analysis}

All statistical analyses were done as analyses of variance (ANOVA) with the Tukey posthoc test as follow-up when significant differences were found (Zar, 1984). For all tests, $\alpha=0.05$ was used as the significance level.

\section{RESULTS}

\section{A. Swim bladder-inner ear relationships}

In $C$. regalis, the minimum distance between the rostral extent of the swim bladder and the otic capsule was $0.22 \pm 0.05 \mathrm{~mm} \mathrm{~cm}^{-1}$, while in L. xanthurus, the distance was $0.74 \pm 0.06 \mathrm{~mm} \mathrm{~cm}^{-1}$ (distance normalized and expressed per centimeter of fish). Thus the distance was significantly less in C. regalis than in $L$. xanthurus $(p<0.05)$.

\section{B. Auditory brainstem responses}

The auditory brainstem response trace characteristics were similar in $L$. xanthurus and $C$. regalis. Responses emerged as a series of negative peaks within the first $20 \mathrm{~ms}$ of stimulus onset (Fig. 1). There were interspecific differences in the auditory bandwidth of $L$. xanthurus and $C$. regalis (Fig. 2). Relative to L. xanthurus, $C$. regalis had a broader frequency range of detection. In our experimental setup, L. xanthurus detected tones up to $700 \mathrm{~Hz}$, while $C$. regalis detected tones up to $2 \mathrm{kHz}$. In the frequency range $200-700 \mathrm{~Hz}$, there were no statistical differences in auditory thresholds between the two species investigated (Fig. 2, $p$ $>0.05)$.

\section{Mass of saccular otoliths}

There were statistically significant differences in saccular otolith mass between $C$. regalis and $L$. xanthurus. The otoliths of $C$. regalis, expressed per centimeter of fish to account for differences in fish size, were larger $\left(4.87 \pm 0.51 \mathrm{mg} \mathrm{cm}^{-1} \mathrm{fish}\right)$ than those of $L$. xanthurus $\left(1.69 \pm 0.14 \mathrm{mg} \mathrm{cm}^{-1}\right.$ fish).

\section{DISCUSSION}

In this study, we found that frequency range of detection correlated with swim bladder proximity to the inner ear. $C$. regalis, a species in which the swim bladder terminates near the ear, has a bandwidth almost three times wider than $L$. xanthurus, a species in which the swim bladder is distant from the ear. Compared to goldfish, however, a well-studied hearing specialist, the auditory thresholds of $C$. regalis were relatively high (Fig. 2). In earlier studies, it has been suggested that the swim bladder enhances sensitivity as well as bandwidth of hearing (von Frisch, 1938; Poggendorf, 1952; Fay and Popper, 1974, 1975). However, results from these sciaenids suggest that the major role of the swim bladder in these species is to only increase sensitivity at higher frequencies (e.g., above $700 \mathrm{~Hz}$ ) and that this, in effect, increases the bandwidth of frequencies over which $C$. regalis can detect sound. Thus, our data, in part, support the hypothesis that the swim bladder may enhance audition when in close proximity to the ear (van Bergeijk, 1967; Kalmijn, 1988; Rogers and Cox, 1988) but suggest that this enhancement may not be over the whole range of hearing of the species.

Sciaenids can be divided into three nontaxonomic "groups" based on swim bladder-ear associations (close, intermediate, and distant), and these correlate with observed differences in frequency range of detection. The data presented for $C$. regalis and L. xanthurus, when pooled with those for B. chyrsoura (Ramcharitar et al., 2004), M. undulatus, and P. chromis (Ramcharitar and Popper, 2004), support an association between swim bladder-ear distance and frequency range of detection (Fig. 3). Interestingly, of these five species, $B$. chyrsoura demonstrates auditory thresholds similar to those of the goldfish (Ramcharitar et al., 2004), and it also has the closest swim bladder-ear association. Therefore, sciaenids are good models for investigating 


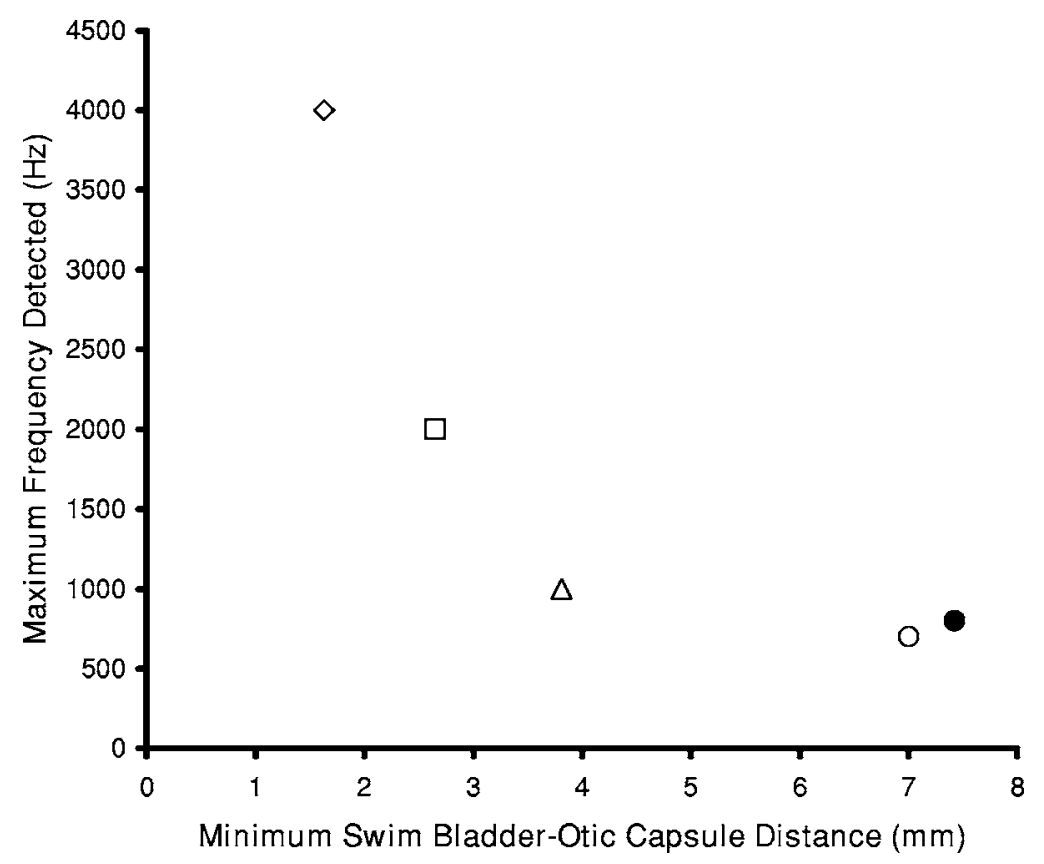

FIG. 3. Relationship between swim bladder-otic capsule distance and maximum frequency detected in sciaenid fishes. These averaged data points include (o) Leiostomus xanthurus and ( $\square$ ) Cynoscion regalis (current study), $(\diamond)$ Bairdiella chrysoura (Ramcharitar

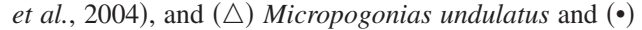
Pogonias chromis (Ramcharitar and Popper, 2004). In general, detection bandwidth improves with proximity of the swim bladder to the inner ear. For all species, the same apparatus, stimuli, and auditory threshold criteria were used.

structure-function relationships in the auditory systems of teleost fish.

Like the sciaenids (although with substantially less interspecific variability), the Atlantic squirrelfish (holocentrids) show three general categories of swim bladder-ear configurations (Nelson, 1955; Popper, 1977). Species in the subfamily Myripristinae have a direct connection between the ear and the anterolateral projections of the swim bladder, while those in the subfamily Holocentrinae can be divided into two groups, one with intermediate swim bladder-ear distances (genus Holocentrus) and one in which the swim bladder is relatively distant from the ear (genera Adioryx and Flammeo). Hearing differences among these categories of squirrelfish may be related to differences in the peripheral auditory system (Tavolga and Wodinsky, 1963; Coombs and Popper, 1979, 1981). Coombs and Popper (1979) demonstrated that Adioryx (no swim bladder-ear connections) has higher auditory thresholds and a more restricted range of frequency detection compared to Myripristis (direct swim bladder-ear connections), and when compared to data for Holocentrus (Tavolga and Wodinsky, 1963), a species with an intermediate swim bladder-ear relationship, it was found that the latter species had hearing abilities that were intermediate, as was predicted.

Interestingly, the auditory thresholds of weakfish and spot were not significantly different for the test frequency range of 200-700 $\mathrm{Hz}$. If the swim bladder in weakfish were in fact stimulating the ear, it would have been expected that this species would show better sensitivity than spot across their common detection range, i.e., 200-700 Hz. Numerous studies on "hearing specialists," including otophysan species [in these, the anterior part of the swim bladder is mechanically coupled to the inner ear by an intervening chain of ossicles, the Weberian ossicles (Weber, 1820)], indicate a reduction in hearing sensitivity when the Weberian ossicles, swim bladder, or otic gas bladder are ablated (e.g., von Frisch, 1938; Poggendorf, 1952; Fay and Popper, 1974,
1975; Fletcher and Crawford, 2001). However, as first observed by Poggendorf (1952), no change in frequency detection range results from such ablation procedures. There is, however, evidence that development of the swim bladder-ear connection coincides with enhanced auditory bandwidth but no change in sensitivity in zebrafish (Danio rerio; Higgs et al., 2003), supporting the enhanced frequency detection seen in the current study. Additionally, in one study (Ladich and Wysoki, 2003), a small reduction in frequency range of detection has been reported for goldfish when its Weberian apparatus is ablated. It is possible that auditory sensitivity is enhanced only when the swim bladder is physically coupled to the inner ear.

The differences observed in frequency detection range between $C$. regalis and $L$. xanthurus may be due in part to morphological differences in inner ear ultrastructure. In particular, a correlation between bundle morphology (height and stereocilia density) and frequency detection has been established for several vertebrate taxa (e.g., Köppl et al., 1998; Gleich and Manley, 2000), although not yet for fish. Studies of inner ear ultrastructure of sciaenid species with different swim bladder-inner ear configurations have shown that species in which this relationship was close also tend to have more stereocilia per bundle on their saccular sensory epithelia (Ramcharitar et al., 2001). As such, the otolithic organs may be frequency tuned. Given the interspecific distinctions in the shapes of the saccular epithelia and their associated ciliary bundle morphology which correlate with swim bladder-inner ear proximity, it is reasonable to propose that these differences may account for (at least in part) the variations observed in frequency range of detection. Further studies on the ultrastructure of the saccular epithelium of the weakfish may shed light on this.

The differences in saccular otolith morphology between C. regalis and L. xanthurus do not appear to impart differential sensitivity to the species. It has been proposed that larger otoliths are likely to confer greater sensitivity to low fre- 
quencies (Lychakov and Rebane, 2000), but no significant differences in sensitivity were observed for the frequency range $200-700 \mathrm{~Hz}$. While it is still possible that otolith size may account for sensitivity differences at even lower frequencies (i.e., $<200 \mathrm{~Hz}$ ), and especially in terms of direct detection of particle motion (largely untested), it is also possible that interspecific differences in saccular otolith size may be responsible, in part, for differences observed here in auditory bandwidth by imparting more displacement when coupled with the pressure transduction provided by the swim bladder. This is supported by recent data from the sleeper goby (Lu and $\mathrm{Xu}, 2002)$ which reveal that bilateral removal of the saccular otoliths significantly reduces hearing sensitivity. This hypothesis and the general function of the otolith vis a vis size and shape need exploration.

In conclusion, the data presented for $C$. regalis and $L$. xanthurus support the hypothesis that teleost fish with swim bladders that lie in close proximity to the inner ear tend to detect sounds at higher frequencies than species lacking such proximity. This correlation between form and function in the teleost auditory system is exemplified by data for several sciaenid species including spot, weakfish, silver perch, Atlantic croaker, and black drum (Fig. 3). While further investigations are needed, we hypothesize that the general relationship in Fig. 3 will hold for other groups of fishes as well, thus demonstrating the functional role of peripheral specializations. This model may also be useful in determining auditory bandwidth in species that are not amenable to physiological testing, such as endangered or even extinct species.

Chao, L. N. (1978). "A basis for classifying western Atlantic sciaenidae," NOAA Tech. Rep. Cir. 415.

Coombs, S., and Popper, A. N. (1979). "Hearing differences among Hawaiian squirrelfish related to differences in the peripheral auditory system," J. Comp. Physiol., A 132, 203-207.

Coombs, S., and Popper, A. N. (1981). "Comparative frequency selectivity in fishes: simultaneously and forward-masked psychophysical tuning curves," J. Acoust. Soc. Am. 71, 133-141.

Crawford, J. D. (1993). "Central auditory neurophysiology of sound producing mormyrid fish: the mesencephalon of Pollimyrus isidori," J. Comp. Physiol., A 172, 1-14.

Davorec, J. E. (1983). "Sciaenid fishes of western peninsula Florida," Florida Department of Natural Resources MRL, St. Petersburg, FL.

Denton, E. J., and Blaxter, J. H. S. (1976). "The mechanical relationship between the clupeid swim bladder, inner ear and lateral line," J. Mar. Biol. Assoc. U.K. 56, 787-807.

Dijkgraaf, S. (1960). "Hearing in bony fishes," Proc. R. Soc. London, Ser. B 152, 51-54.

Fay, R. R. (1988). Hearing in Vertebrates: A Psychophysics Databook (HillFay, Winnetka, IL).

Fay, R. R., and Popper, A. N. (1974). "Acoustic stimulation of the ear of the goldfish,” J. Exp. Biol. 61, 243-260.

Fay, R. R., and Popper, A. N. (1975). "Modes of stimulation of the teleost ear," J. Exp. Biol. 62, 379-387.

Fletcher, L. B., and Crawford, J. D. (2001). "Acoustic detection by sound producing fishes (Mormyridae): the roll of gas-filled tympanic bladders," J. Exp. Biol. 204, 175-183.

Gleich, O., and Manley, G. A. (2000). "Hearing organs of birds and crocodilian," in Comparative earing: Birds and Reptiles, edited by R. J. Dool- ing, R. R. Fay, and A. N. Popper (Springer-Verlag, New York), pp. 70138 .

Hawkins, A. D., and Myrberg, A. A. (1983). "Hearing and sound communication underwater," in Bioacoustics - A Comparative Approach, edited byB. Lewis (Academic, London), pp. 347-405.

Higgs, D. M. (2002). "Development of the fish auditory system: How do changes in auditory structure affect function?" Bioacoustics 12, 180-182.

Higgs, D. M., Rollo, A. K., Souza, M. J., and Popper, A. N. (2003). "Development of form and function in peripheral auditory structures of the zebrafish (Danio rerio)," J. Acoust. Soc. Am. 113, 1145-1154.

Kalmijn, A. J. (1988). "Hydrodynamic and acoustic field detection," in Sensory Biology of Aquatic Animals, edited by A. Atema, R. R. Fay, A. N. Popper, and W. N. Tavolga (Springer-Verlag, New York), pp. 131-149.

Köppl, C., Gleich, O., Schwabedissen, G., Siegl, E., and Manley, G. A. (1998). "Fine structure of the basillar papilla of the emu: implications for the evolution of avian hair cell types," Hear. Res. 355, 99-112.

Ladich, F., and Wysoki, L. E. (2003). "How does tripus extirpation affect auditory sensitivity in goldfish?." Hear. Res. 182, 119-129.

Lu, Z., and Xu, Z. (2002). "Effects of removal of saccular otoliths on hearing sensitivity in the sleeper goby (Dormitator latifrons)," J. Comp. Physiol., A 188, 595-602.

Lychakov, D. V., and Rebane, Y. T. (2000). "Otolith regularities," Hear. Res. 143, 83-102.

Mann, D. M., Lu, Z., and Popper, A. N. (1997). "A clupeid fish can detect ultrasound," Nature (London) 389, 341.

McCartney, B. S., and Stubbs, A. R. (1971). "Measurements of the acoustic target strengths of fish in dorsal aspect including swim bladder resonance," J. Sound Vib. 15, 397-420.

Nelson, E. M. (1955). "The morphology of the swim bladder and auditory bulla in the Holocentridae," Zoologica (N.Y.) 37, 121-130.

Poggendorf, D. (1952). "Die absolute Hörschwelle des Zwergwelses (Amiurus nebulosus) und Beiträge Zur Physik des Weberschen Apparates der Ostariophysan." Z vergl. Physiol. 34, 222-257.

Popper, A. N. (1977). "A scanning electron microscopic study of the sacculus and lagena in the ears of fifteen species of teleost fishes," J. Morphol. 153, 397-418.

Popper, A. N., and Fay, R. R. (1999). "The auditory periphery in fishes," in Comparative Hearing: Fish and Amphibians, edited by R. R. Fay and A. N. Popper (Springer-Verlag, New York), pp. 43-100.

Ramcharitar, J., and Popper, A. N. (2004). "Masked auditory thresholds in sciaenid fishes: a comparative study," J. Acoust. Soc. Am. 116, 16871691.

Ramcharitar, J., Higgs, D. M., and Popper, A. N. (2001). "Sciaenid inner ears: a study in diversity," Brain Behav. Evol. 58, 152-162.

Ramcharitar, J. U., Deng, X., Ketten, D., and Popper, A. N. (2004). "Form and function in the unique inner ear of a teleost: the silver perch (Bairdiella chrysoura)," J. Comp. Neurol. 475, 531-539.

Rogers, P. H., and Cox, M. (1988). "Underwater sound as a biological stimulus," in Sensory Biology of Aquatic Animals, edited by A. Atema, R. R. Fay, A. N. Popper, and W. N. Tavolga (Springer-Verlag, New York), pp. 131-149.

Tavolga, W. N., and Wodinsky, J. (1963). "Auditory capacities in fishes. Pure tone thresholds in nine species of marine teleosts," Bull. Am. Mus. Nat. Hist. 126, 177-240.

van Bergeijk, W. A. (1967). "The evolution of vertebrate hearing," Contrib Sens Physiol. 2, 1-49.

von Frisch, K. (1938). "The sense of hearing in fish," Nature (London) (London) 141, 8-11.

Weber, E. H. (1820). "De aure et auditu hominis et animalium, Pars I," De Aure Animalium Aquatilium. Leipzig.

Yan, H. Y., Fine, M. L., Horn, N. S., and Coton, W. E. (2000). "Variability in the role of the gasbladder in fish audition," J. Comp. Physiol., A 186, 435-445.

Zar, J. H. (1984). Biostatistical analysis, 2nd ed. (Prentice-Hall, Englewood Cliffs, NJ). 